\title{
Design on the Curriculum Reform for Experimental Classes of Secondary Majors in Electric Power System
}

\author{
Zhang Xilin ${ }^{1, a}$, Xu Shouchen ${ }^{2, b}$ \\ 1. State Grid Jilin Electric Power Company Limited Changchun Power Supply Company , \\ Changchun, 130021, China \\ 2. State Grid the Senior Training Center, Beijing, 100085, China \\ aemail: xilinzhang@21cn.com, bemail: shouchen-xu@sohu.com
}

\begin{abstract}
Keywords: Electric Power System; Secondary Major; Experimental Class; Curriculum Arrangement
\end{abstract}

\begin{abstract}
In this thesis, the training objectives and curriculum arrangement for experimental classes of secondary majors in electric power system in universities are discussed based on the fact that the construction of smart power grid becomes a national strategy as well as the actual situation on the implementation of Three-Intensive and Five-Large Reform (refers to the intensive management of human resource, finance and materials as well as the system of large-scale planning, construction, operation, overhaul and marketing) carried out by State Grid Corporation of China, moreover, Some issues, such as the combination with Excellent Engineer Plan and content of lectures, are discussed. Urgency of the methods mentioned is indicated in the actual requirements of power grid enterprises on the quality of their staff.
\end{abstract}

\section{Introduction}

The construction of a Unified and Strong Smart Power Grid has been involved in government work report for several years in a row, which indicates that the construction of a smart power grid has become a national strategy. Now, the work is proceeding vigorously around the country and will become the main form of power grid construction in China for sure in future. In 2012, the Three-Intensive and Five-Large Reform was completed, indicating that most of China's power grid enterprises should operate according to the new management mode. Facing new technical challenges and new mode for operation management, the curriculum arrangement for experimental classes of secondary majors in electric power system shall be reformed to prepare graduates for better meeting the requirements in practical work. In this thesis, the training objectives and the principle of curriculum arrangement for experimental classes of secondary majors in electric power system are put forward targeting the above-mentioned situation and problems and based on the actual needs of employers; moreover, some issues, such as being in combination with Excellent Engineer Plan and content of lectures, are discussed and implementation scheme of principle are proposed. However, during implementation, educators should make a secondary scheme and design based on relevant regulations and policies.

\section{Training Objectives ${ }^{[1,2]}$}

Object 1: Graduates with high skill in field work. They should be highly competitive in the job market. After entering a company, they should be able to do many practical works independently such as design, planning, operation maintenance and engineering construction, which means that they are highly capable in practical work;

Object 2: Graduates with all-round professional skills or inter-disciplinary professional skills. They should be highly adaptable and can fit the work in many departments, including department for power dispatching control (major of dispatching operation and automation for master station), department for operation and maintenance (operation and maintenance of substation, major of automation for the repair and test of power plants and substations as well as the repair and test of 
relay protection), department for information and communication (the operation and maintenance of communication system as well as the overhaul of information service), economic and technical department (planning and review, the design of secondary system as well as planning and operation), department for development planning (the planning and management of secondary system), custom service center (major for measurement), department for fundamental construction (the engineering management of secondary system), department for the service of electric vehicle (the operation and maintenance of charging facilities) and training center;

Object 3: Graduates with striking features. They should be highly capable of doing technical innovation and can keep discovering, analyzing and addressing problems in practice, consistent with the requirements of innovation-based enterprises and society; they should possess solid theoretical and practical knowledge for further study, which can provide professional knowledge and practical skills for master's degree program and doctor's degree program;

Object 4: Graduates with professional and management skill. Their professional knowledge and comprehensive quality are consistent with the requirements in the structural reform of State Grid Corporation of China, namely that they are inter-disciplinary talents based on expertise, labor skill, scientific and technical innovation as well as management skill, possessing the most fundamental knowledge and skills in communication and coordination.

\section{Combination with the Excellent Engineer Plan ${ }^{[3]}$}

Teaching based on practice is stressed in the Excellent Engineer Plan for universities (the teaching mode of $3+1$ ). The policies and regulations on companies participating in the Excellent Engineer Plan shall be established and completed. The enthusiasm, initiative and creativity of enterprises in taking part in this plan shall be fully mobilized, which will ensure the implementation of this plan in many aspects such as field work, tutor, teaching based on practice, subject, organization, etc. The plan needs a lot of teachers in field work, so it is very important to formulate a standard for staffing as well as to establish and implement a performance evaluation mechanism for teachers in field work. On the one hand, the absolute safety of students shall be ensured in teaching, so it is necessary to provide enough training on safety education for students before they enter a production site and ensure a whole-day guardianship by safety officers with a strong sense of responsibility and great professional skills; on the other hand, the primary and secondary equipments in power transmission and distribution shall work safely and smoothly without any failure or anomaly in power grid or electric power system caused by human factors, such as touch in accident. The content of courses and subjects during teaching in field work shall be fixed basically, but they shall also be changed and completed with technological progress. The assessment on teaching in the Excellent Engineer Plan shall be substantial but not superficial. Before teaching, program for assessment shall be distributed to all students to make sure that they know about the content and requirements for assessment clearly, which enables them to learn and prepare for the assessment in a targeted way.

A. Taking part in the construction of smart substations

The construction of smart substations contains several key points, including specific working place and tasks, clear lines of responsibility on safe production for managerial staff and engineers, preparation work before project, technical measures on the safety of work sites, dangerous points and control measures, the installation and debugging of secondary equipments for substations, acceptance test of projects and putting into operation, etc. The installation and debugging of secondary equipments for substations mainly include the stability of screens for secondary equipments, the laying and connection of control cables and computer cables, the electrical tests on secondary equipments and relevant primary equipments as well as the joint debugging with the system of automatic master stations in relevant power control centers. Through a whole process of installation and debugging for a substation, the students, based on perception, can learn the basic procedure for the equipments, installation, debugging during the construction of a substation in an all-round way. 
B. Using the rooms for practical training in power grid enterprises

Generally, the existing rooms for practical training in power grid enterprises are built according to real smart grid, including smart substation, smart power transmission and distribution, distributed power connection, smart building or home furnishing, the supporting system for dispatching technique, etc. Moreover, the expandability of the functions of existing training rooms is taken into consideration during construction, so the functions of these training rooms will be completed with the development in the construction of smart grid.

The effects and timeliness of teaching for experimental classes may be improved with the using of rooms for practical training in power grid enterprises, meanwhile, the utilization of teaching resources in these training rooms will also be improved.

C. Visiting leading company's production bases for equipments of smart substations

Universities specializing in electric power, if conditions permit, may organize students in experimental classes of secondary majors in electric power system to visit leading company's production bases for equipments of smart substations, inviting engineers and technicians to make an introduction to products' principle, technical features, application area and developing trend in the future.

D. Using the dispatcher training simulator system in provincial power grid companies.

Generally, provincial power grid companies should have Dispatcher Training Simulator System (DTS) and provincial power dispatching centers should have master station system, moreover, each power supply company should have remote work station. The DTS of provincial power dispatching centers and the remote work stations of power supply companies shall be fully used, providing practical trainings for students in the operation analysis, switching operation and failure prediction on a working power grid (electric system), which will bring more ideal effect.

E. Simulation test on safety behaviors

In courses on safety training, the mode of simulation test on safety behaviors, the content of training and the evaluation system in provincial power grid companies shall be fully used, laying a solid foundation on safe production for students during their learning.

F. A tutor group jointly formed by university and enterprise shall be established, which will provide conditions for students in tackling key problems in science and technology from the second year in university. Each tutor group should have two or three tutors, including university teachers and engineers from enterprises, who may direct students totaling four to six. The subjects in tackling key problems in science and technology could be based on many aspects, such as real science and technology projects, subjects on tackling key problems in science and technology in mass quality control and in engineering, cutting-edge theory and research, etc.

\section{The category of lecture ${ }^{[4-5]}$}

1) Lectures on automation, relay protection, communication, electronic instrument transformer and the guidelines on technology of smart power grid

State Grid Corporation of China is leading the trend of constructing smart power grid. The lectures on automation, relay protection, communication, electronic instrument transformer and the guidelines on technology of smart power grid, provided by State Grid Corporation of China to all the staff in the system, shall be collected and compiled into teaching materials such as books and DVDs. Through audio-visual teaching, students in their third year and fourth year can get access to the most authentic, timely and definite knowledge on smart power grid, narrowing the gap between teaching and practice to a large degree.

2) Lectures on the methodology of technical innovation

Experts with outstanding achievements in technical innovation shall be invited to give lectures on the methodology of technical innovation to first-year students and second-year students. On the one hand, students will be motivated and enlightened by these lectures, developing enthusiasm, initiative and creativity in learning and work; on the other hand, they can learn some fundamental factors such as methods for technical innovation. Not only does this method meet the requirement 
of innovative development, it also lays a solid foundation for the third-year students and fourth-year students in their learning and work in future. These lectures should cover a wide range of aspects, including Total Quality Control (TQC), thesis writing, technical innovation (tackling key problems in science and technology), knowledge of patent, software copyright and technical standards (including project approval, drafting, advice seeking, submitting for approval, issuing, implementing, rechecking, etc.)

\section{Conclusion}

The initiatives, including an in-depth research on the training objectives and curriculum arrangement for experimental classes of secondary majors in electric power system in universities, the continuous update on the content of field teaching as well as the combination of lectures and the Excellent Engineer Plan, shall make the education to students of secondary majors in electric power system better in facing the challenges of new technologies and meeting the requirements of a new operation management mode as well as prepare students for the construction of smart power grid and the new management procedure brought by the Three-Intensive and Five-Large Reform. The urgency of the above-mentioned methods is indicated in the actual requirements of power grid enterprises on the quality of their staff.

Explores and Practice of Power System Relay Protection Curriculum Proj ect Pattern

\section{References}

[1] He Ruiwen,Chen Shaohua. Explores and Practice of Power System Relay Protection Curriculum Project Pattern[J]. Proceedings of the Chinese Society of Universities for Electric Power System and its Automation,2009,21(3):125-128.

[2] He Ruiwen,Chen Shaohua. The Reform and Construction of Modern Electric Power Relay Protection Courses[J]. Journal of Electrical \& Electronic Education, 2004, 26(3):20-21,25.

[3] Chen Shuyong, Song Shufang, Li Lanxin, Shen Jie. Survey on Smart Grid Technology [J]. Power System Technology,2009,33(8):1-7.

[4] Wang Qingzhu, Zhang Huanlong Ma Yuquan. The Practical Teching Reform of Electrical Engineering and Its Automation Specialty [J]. Journal of Hebei University of Science \& Technology,2007,21(4):63-65,69.

[5] Ye Zhipan, JinPeihua. A Review of Studiees on Practice Teaching of Engineering Education in China [J]. Research in Higher Educaiton of Engineering,2007,25(4):74-77. 